\title{
ARTICLE
}

\section{Luminescent $\mathrm{CaTiO}_{3}: \mathrm{Yb}$,Er Nanofibers Co-conjugated with Rose Bengal and Gold Nanorods for Potential Synergistic Photodynamic/Photothermal Therapy}

Received 00th January 20xx Accepted 00th January 20xx DOI: $10.1039 / \times 0 \times x 00000 x$

www.rsc.org/

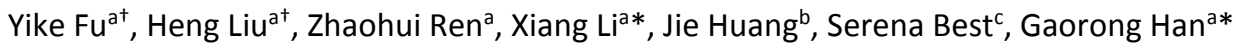

Photodynamic therapy (PDT) and photothermal therapy (PTT) have been explored widely for application in cancer treatment. In this work, we describe the synthesis of $\mathrm{CaTiO}_{3}: \mathrm{Yb}, \mathrm{Er}$ (CTO) nanofibers co-conjugated with Rose Bengal (RB) and gold nanorods (AuNRs), which offer the potential for combined upconversion photoluminescence (UCPL) and enhanced, synergistic PDT and PTT. Based on this delivery platform, RB and AuNRs served as the PDT and PTT agents, respectively. RB and AuNRs have strong and well-matched absorption with the green and red emissions of UCPL CTO nanofibers respectively, hence a single $980 \mathrm{~nm}$ continuous wave laser with deep tissue penetration can be employed to allow PDT and PTT to occur simultaneously. The nanocomposite can effectively convert the near-infrared (NIR) radiation from the laser into a combination targeted hyperthermia and generation of reactive oxygen species (ROS). In comparison with PDT alone, the combined PDT/PTT treatment showed significantly enhanced suppression of the viability of Hep G2 cells in vitro, demonstrating its potential for use in oncology.
\end{abstract}

\section{Introduction}

Mortality due to cancer is increasing year on year and in 2012, an estimated 14.1 million new cancer cases and 8.2 million cancer deaths occurred worldwide. ${ }^{1}$ Conventional cancer treatments including chemotherapy and radiotherapy are associated with a number of limitations, such as toxic side effects and the tendency towards multidrug resistance (MDR).2, 3 These treatments may also fail to eradicate the tumor as expected. In recent years, drug-free phototherapy including photothermal therapy (PTT) and photodynamic therapy (PDT) have attracted increasing attention due to their unique advantages, which include low toxicity, low level side effects, possibilities for remote control, potential for minimally invasive intervention and avoidance of chemo-resistance. ${ }^{4-9}$ Near-infrared (NIR) illumination has been recognized to be ideal for phototherapy applications due to its deep tissue penetration. Previous reports describe a penetration depth of at least $10 \mathrm{~cm}$ through breast tissue, and $4 \mathrm{~cm}$ of skull/brain tissue or deep muscle using NIR laser sources. ${ }^{10}$ In general, PTT uses photo-absorbing agents to convert the electromagnetic energy of NIR light into localised heat and thereby destroy

\footnotetext{
a. State Key Laboratory of Silicon Materials, School of Materials Science and Engineering, Zhejiang University, Hangzhou, Zhejiang 310027, P. R. China.

b. Department of Mechanical Engineering, University College London, London WC1E 7JE, UK.

c. Department of Materials Science and Metallurgy, University of Cambridge,

Cambridge CB3 OFS, UK.

d.*E-mail: xiang.li@zju.edu.cn; $\underline{h g r @ z j u . e d u . c n}$

+ Authors contributed equally to this work.
}

tumors via hyperthermia. For PDT, visible light converted by up-conversion nanomaterials under NIR light can activate photosensitizers (PSs) to generate cytotoxic reactive oxygen species (ROS), such as singlet oxygen $\left({ }^{1} \mathrm{O}_{2}\right)$, superoxide anions, and hydrogen peroxide, and thus reduce significantly the viability of tumor cells. ${ }^{11-13}$ However, issues such as low potency, the requirement for excessive laser power density, high oxygen dependence and long-term skin photosensitization have significantly hindered the clinical translation of both techniques. ${ }^{14}$

Recent investigations have endeavored to develop synergistic therapeutic approaches in which PTT and PDT are combined effectively and simultaneously. Compared with individual treatment protocols, synergistic combined use of PTT and PDT can reduce the drawbacks of each method when used alone. Various types of nanocarriers, including gold nanomaterials ${ }^{8}, 15$, graphene ${ }^{16}$, and conjugated polymers ${ }^{17}$, have been tested for combined PDT and PTT. For example, PDT/PTT dual-mode therapeutic agents based on Chlorin e6 (Ce6) modified poly(dopamine) nanospheres with high ROS generation and photothermal conversion efficiency was reported to offer significantly improved therapeutic effects as compared with PDT and PTT alone. ${ }^{11}$ 


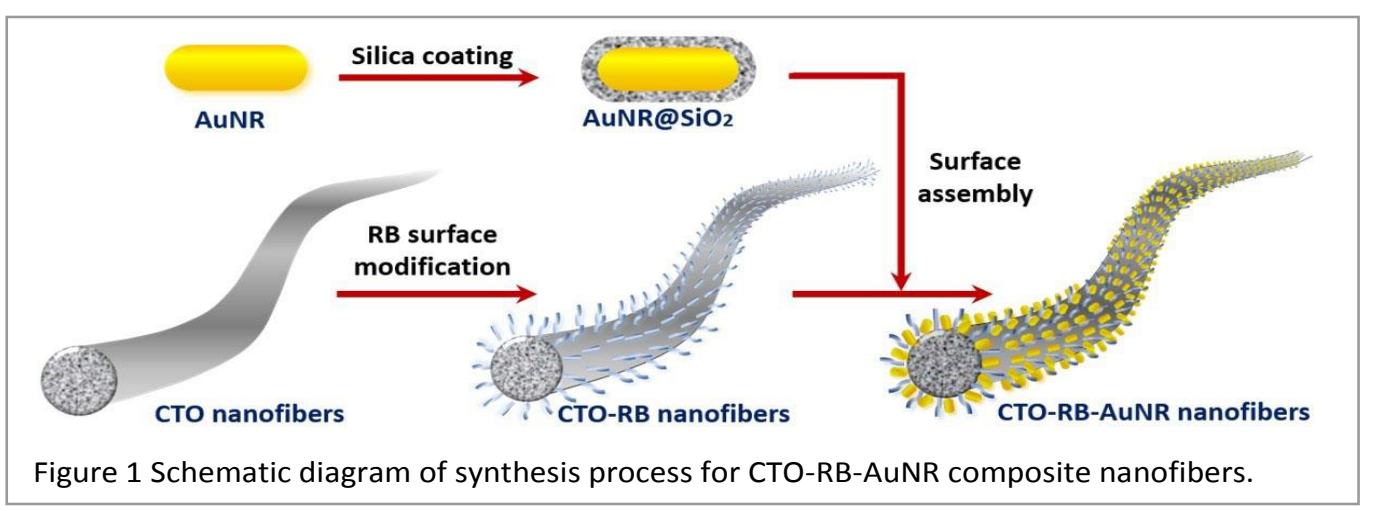

To date, a variety of ultraviolet light or visible light responsive photosensitizers including Ce6 $(660 \mathrm{~nm})$ and Photofrin $\left(630 \mathrm{~nm}\right.$ ) have been investigated. ${ }^{18-20}$ In such regions of the electromagnetic spectrum, light penetration is hindered due to endogenous chromophores and light scattering. ${ }^{21}$ Therefore, two or more separate spectra with different wavelengths would normally be utilized for sequential excitation of each therapeutic step because of the absorption mismatch between photosensitizers and photothermal agents. However, sequential irradiation complicates and prolongs the treatment process owing to difficulties in focusing the two laser beams at the same position. Hence, constructing a novel therapeutic platform which can be triggered by a single wavelength laser for simultaneous PDT and PTT has become a hot topic in cancer therapy.

Another problem associated with PDT and PTT monotherapies is the target specificity of particulate PS/photothermal agents or their carriers. The low efficiency of delivery of $\mathrm{PS} /$ photothermal agents to tumour sites limits effectiveness of the treatment. Implantable therapeutic platforms, such as hydrogels and polymeric films etc., have been considered as an ideal substitutes for delivering PS/photothermal agents, which can achieve a much higher concentration of agents at the cancerous site and low systemic agent levels simultaneously. 22,23 The design of phototherapeutic platforms based on the concept of localized drug delivery can maximize the effectiveness of PDT/PTT while minimizing the side effects of conventional therapy.

Calcium titanate $\left(\mathrm{CaTiO}_{3}\right)$ is a ceramic with excellent biocompatibility for medical implants. ${ }^{24-26}$ The construction of rare earth doped $\mathrm{CaTiO}_{3}$ nanofibers in our previous research also demonstrated the potential of capitalizing on the UCPL behaviour of $\mathrm{CaTiO}_{3}$ for drug delivery applications. ${ }^{27,} 28$ The rare earth ions doped, generally occupy the Ca site and the asymmetric perovskite structure of $\mathrm{CaTiO}_{3}$ can effectively prohibit the possible diffusion of rare earth elements, which ensures the photoluminescent properties and avoids potential toxicity. In an advancement our previous work, an implantable nanocomposite based on these $\mathrm{CaTiO}_{3}$ nanofibers has now been developed that allow us to combine PDT and PTT synergistically, in a way that offers the potential for a drug-free treatment regime. Rose Bengal (RB), a typical photodynamic therapeutic agent in the visible region, was attached to the surface of electrospun nanofibers comprising up-conversion photoluminescence (UCPL) $\mathrm{CaTiO}_{3}: \mathrm{Yb}, \mathrm{Er}$ (CTO) (Figure 1). In addition, silica-coated gold nanorods (AuNR@SiO ${ }_{2}$ ) were prepared and anchored onto the nanofibers to serve as the photothermal agent. Using a single, $980 \mathrm{~nm}$ continuous wave laser, the red and green emissions from CTO nanofibers were absorbed by RB and AuNRs, generating a combination of heat and reactive oxygen species, respectively. The photothermal and photodynamic properties were analyzed systematically and an in vitro Hep G2 liver cancer cell model was utilized to evaluate the effects of the combined therapy compared with monotherapy. This work aims to find an effective approach for synergistic cancer therapy with superior efficacy.

\section{Results and discussion}

\subsection{Characteristics of СТO nanofibers}

Electrospun CTO nanofibers were prepared using a sol-gel precursor and were calcined at $700{ }^{\circ} \mathrm{C}$. It has been shown previously that this provided fibers with the optimum combination of surface roughness and crystallinity (without the formation of a second phase) in the case of subsequent attachment of active drug molecules. ${ }^{27}$ Representative
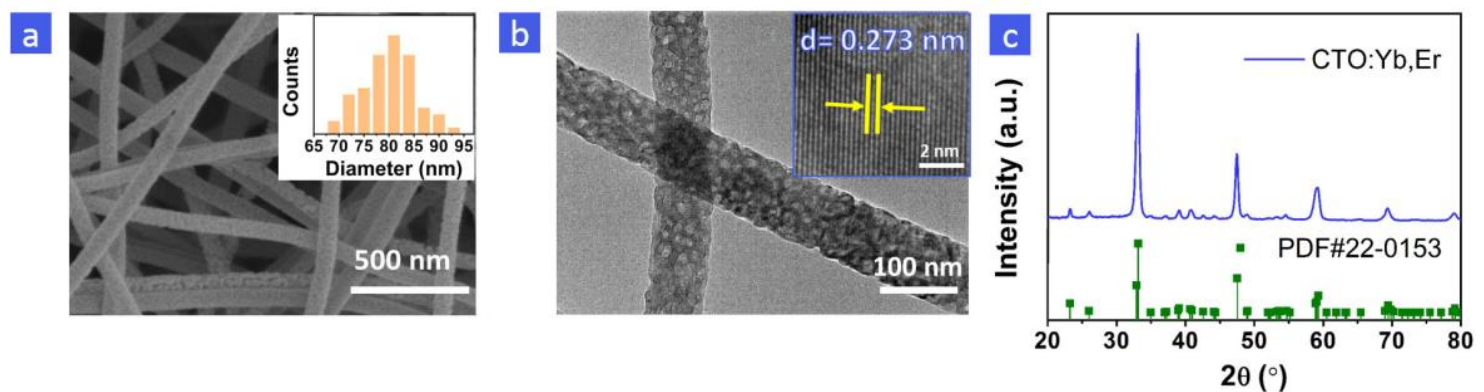

Figure 2 (a) SEM image and diameter distribution (inset) (b) TEM image and HRTEM pattern (inset) and (c) XRD pattern of calcined CTO:Yb,Er nanofibers. 
scanning electron micrographs and transmission electron micrographs of the fibers produced in this study are shown in Figures $2 a$ and $2 b$ respectively. The inset image in Figure $2 a$ shows that mean diameter of CTO nanofibers is approximately $80 \mathrm{~nm}$. Lattice imaging revealed a d-spacing of $0.273 \mathrm{~nm}$, which is attributable to the (200) planes of $\mathrm{CaTiO}_{3}$ (JCPDS No.22-0153). Figure 2c shows well-defined X-ray diffraction peaks attributable to highly crystalline $\mathrm{CaTiO}_{3}$ (JCPDS No.220153). The close match of the indexed reflections with the stick pattern suggests the absence of any extraneous $\mathrm{Er}$ or $\mathrm{Yb}$ compounds.

\subsection{Synthesis of CTO-RB nanocomposite}

To construct the CTO-RB composite, СTO nanofibers were first modified with amino groups to enhance the interaction between the two phases. FTIR spectra of CTO and amino-modified СTO nanofibers $\left(\mathrm{CTO}-\mathrm{NH}_{2}\right.$ ) are shown in Figure 3a. For pure CTO nanofibers, a characteristic peak at $548 \mathrm{~cm}^{-1}$ can be ascribed to a Ti$\mathrm{O}$ vibration. After modification using amino groups, a new peak appeared which can be assigned to $\mathrm{N}-\mathrm{H}$ asymmetric bending vibration at $1560 \mathrm{~cm}^{-1}$, indicating the successful functionalization of CTO nanofibers with amino groups.

To improve the reactivity of the carboxyl group for subsequent conjugation between RB and CTO nanofibers, the benzyl carboxyl group of RB was replaced with hexanoic acid (HA) to obtain RBHA. ${ }^{29}$ The FTIR spectrum of RB-HA in Figure 3a shows that a new peak corresponding to the $\mathrm{C}=\mathrm{O}$ stretching vibration mode of the carboxyl group at $1720 \mathrm{~cm}^{-1}$, confirming the successful preparation of RB-HA.
The nanofibers and photosensitizers were conjugated via electrostatic bonding between the amino group of CTO- $\mathrm{NH}_{2}$ nanofibers and the carboxyl group of RB-HA. The $\mathrm{C}=\mathrm{O}$ stretching vibration at $1720 \mathrm{~cm}^{-1}$ is absent in the FTIR spectrum of RBHA bound CTO nanofibers (CTO-RBHA, CTO-RB), whereas carboxylate bands at 1556 and $1390 \mathrm{~cm}^{-1}$ are detected, which indicates that proton transfer from the carboxylic acid of RB-HA to amino groups of the nanofibers has taken place. ${ }^{30}$ The findings confirm that RB-HA adsorbed on the nanofibers via electrostatic interaction. The zeta potential of pure CTO nanofibers is $-16 \mathrm{mV}$. Amino modification induced positive zeta potential of approximately $+21.7 \mathrm{mV}$ for CTO$\mathrm{NH}_{2}$ nanofibers, and the introduction of RB-HA neutralized part of the positive charge on CTO- $\mathrm{NH}_{2}$ nanofibers, resulting in a lower zeta potential of approximately $+6.5 \mathrm{mV}$ (Figure $3 \mathrm{~b}$ ). The number of RBHA molecules attached to CTO nanofibers was determined to be $1.77 * 10^{16} \mathrm{RB}$ molecules per milligram of CTO nanofibers (Figure S1).

Under $980 \mathrm{~nm}$ excitation, the СТО nanofibers emit green light $\left({ }^{2} \mathrm{H}_{11 / 2},{ }^{4} \mathrm{~S}_{3 / 2} \rightarrow{ }^{4} \mathrm{I}_{15 / 2}\right.$ transition $)$ and red light $\left({ }^{4} \mathrm{~F}_{9 / 2} \rightarrow{ }^{4} \mathrm{I}_{15 / 2}\right.$ transition) (Figure $4 \mathrm{a}$, blue trace) confirming successful doping of rare earth ions into $\mathrm{CaTiO}_{3}$ crystal. The synergistic therapy platform is constructed based on the selective energy transfer from UCPL of CTO nanofibers to photosensitizers and AuNRs. RB was chosen in this study, because its absorption band at $\sim 540 \mathrm{~nm}$ is overlapped by the green emission of CTO nanofibers when excited using radiation of $980 \mathrm{~nm}$ wavelength (Figure 4a). The absorption peaks of the CTO-RBHA complex around $500-600 \mathrm{~nm}$ present similar characteristics to the spectrum of pure RB-HA. The red shift observed may be attributed to the electron donating nature of the amine group. ${ }^{31}$ Therefore, the emission of $\sim 540 \mathrm{~nm}$ was strongly
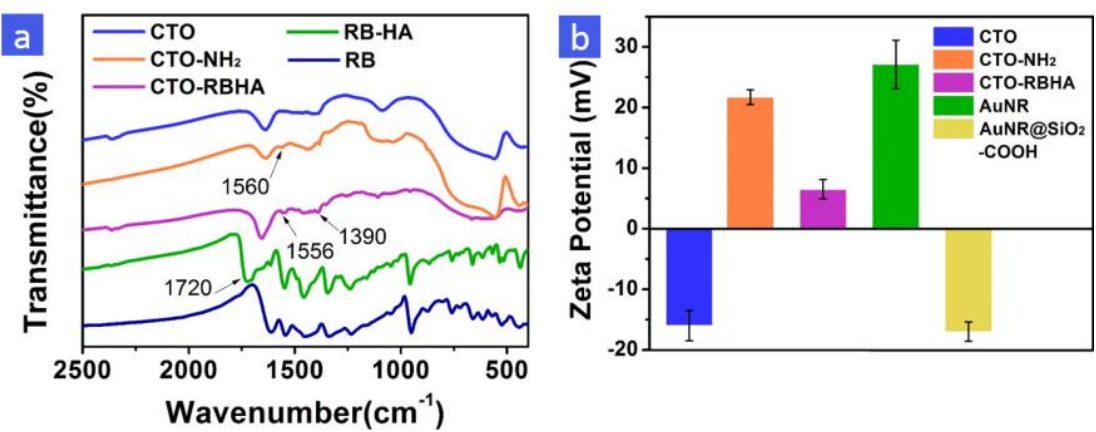

Figure 4 (a) FTIR spectra of RB molecules, RB-HA, CTO, CTO- $\mathrm{NH}_{2}$ nanofibers and CTO-RBHA nanocomposite; (b) Zeta potentials of CTO, CTO-NH ${ }_{2}, \mathrm{CTO}-\mathrm{RBHA}$, AuNRs and $\mathrm{AuNR} @ \mathrm{SiO}_{2}-\mathrm{COOH}$.
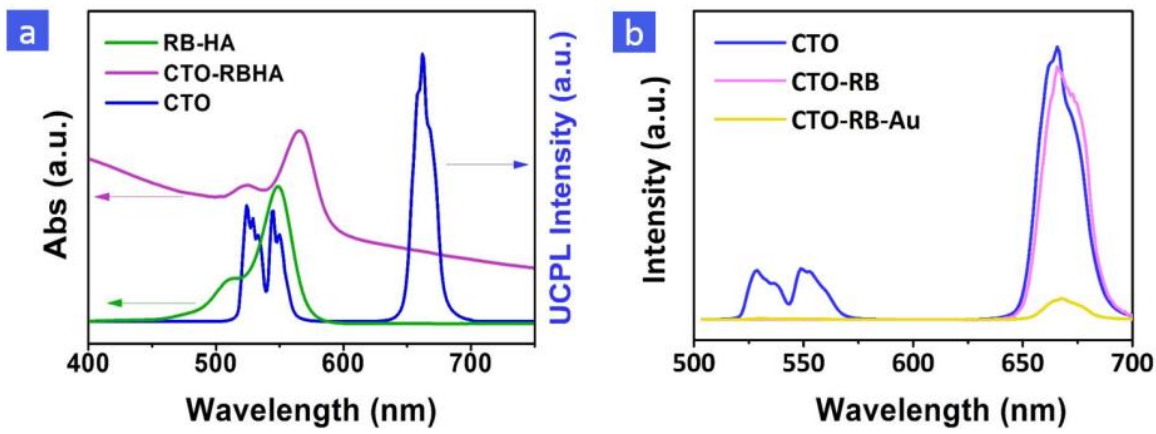

Figure 3 (a) UV-vis absorption spectra of RB-HA and CTO-RBHA, and upconversion emission spectrum of CTO nanofibers under $980 \mathrm{~nm}$ irradiation; (b) Up-conversion emission spectra of CTO, CTO-RB and CTO-RB-Au under $980 \mathrm{~nm}$ irradiation. 

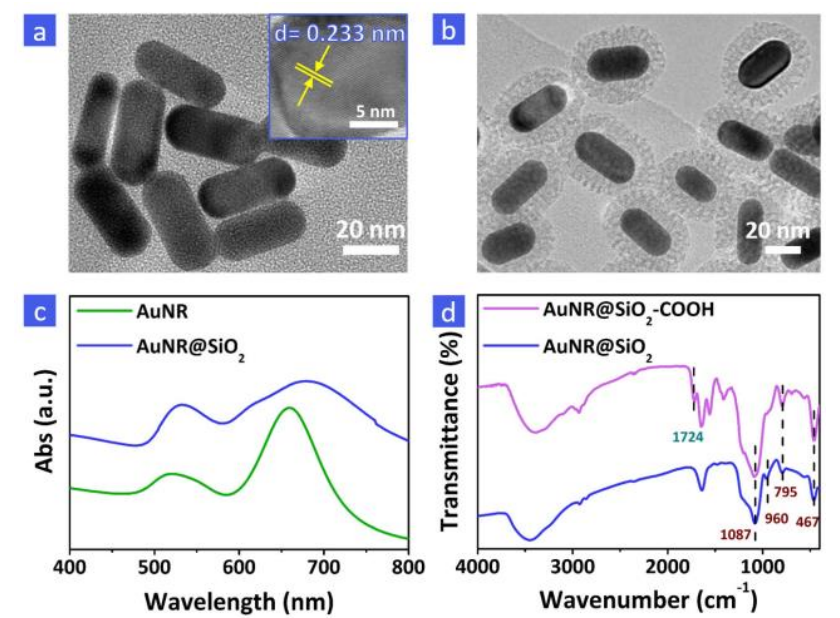

Figure 6 (a) TEM and HRTEM (inset) images of AuNRs; (b) TEM image of AuNRs@SiO ${ }_{2}$, (c) UV-vis absorption spectra of AuNRs and AuNRs@SiO , (d) FTIR spectra of AuNR@SiO ${ }_{2}$ and AuNR@SiO $2-\mathrm{COOH}$.

quenched while the emission of CTO nanofibers $\sim 660 \mathrm{~nm}$ was almost unchanged after RB bonding, as demonstrated in Figure $4 \mathrm{~b}$, indicating the effective absorption of green emission by $\mathrm{RB}$ molecules.

\subsection{Characteristics of CTO-RB-Au composite}

AuNRs were prepared by a seed-mediated method with modifications. ${ }^{32}$ The as-prepared AuNRs were coated with a bilayer of CTAB, which acts as a stabilizer. The CTAB-coated AuNRs had an average length of $~ 33.3 \pm 7$ and a width of $14.4 \pm 4 \mathrm{~nm}$. The particles are crystalline with a d-spacing of $0.233 \mathrm{~nm}$, corresponding to the (111) lattice plane of gold (JCPDS No. 04-0784) (Figure 5a). While gold is biologically inert and surface-bonded CTAB has low cytotoxicity, detached CTAB is a harmful surfactant. ${ }^{33,34}$ To reduce the potential hazards associated with this and also to improve photothermal stability, AuNRs were coated with silica. ${ }^{35,36}$ The CTAB layer acts as an organic template for the silica coating via a modified Stöber method. As shown in Figure 5b, the AuNRs obtained were coated with a $\mathrm{SiO}_{2}$ layer with a thickness of approximately $10 \mathrm{~nm}$. The corresponding UV-vis absorption spectra of AuNRs and AuNRs@SiO 2 further confirm the successful silica coating of AuNRs (Figure 5c). The AuNRs have a weak transverse surface plasmon resonance (TSPR) band at $520 \mathrm{~nm}$ and a strong longitudinal surface plasmon resonance (LSPR) band at $660 \mathrm{~nm}$ (as will be discussed below). After coating with $\mathrm{SiO}_{2}$, a clear red shift of $\sim 20 \mathrm{~nm}$ in the LSPR band compared with that of uncoated AuNRs was observed, which is attributed to the increase in the local refractive index of the surrounding medium after replacing $\mathrm{CTAB}$ with $\mathrm{SiO}_{2}$ shell. ${ }^{37,} 38$

In order to anchor the AuNRs on the CTO-RB nanofibers, the AuNR@SiO 2 was modified with - $\mathrm{COOH}$. The FTIR spectrum of AuNR@SiO ${ }_{2}$ reveals asymmetric stretching of Si-O-Si at 1087 $\mathrm{cm}^{-1}$, symmetric stretching of Si-O-Si at $795 \mathrm{~cm}^{-1}$, a bending vibration for $\mathrm{Si}-\mathrm{O}-\mathrm{Si}$ at $467 \mathrm{~cm}^{-1}$ and symmetric stretching vibrations of Si-O bonds in the $\mathrm{Si}-\mathrm{OH}$ groups at $960 \mathrm{~cm}^{-1}$, which can be attributed to the $\mathrm{SiO}_{2}$ layer (Figure $5 \mathrm{~d}$ ). ${ }^{38,39}$ After being modified with - $\mathrm{COOH}$ groups, a clear vibrational peak at 1724 $\mathrm{cm}^{-1}$ was observed, which can be assigned to the $\mathrm{C}=\mathrm{O}$ stretching band of carboxylic groups. The zeta potential of AuNRs was found to be approximately $+27.1 \mathrm{mV}$. This was due to the bilayer of CTAB on the nanorod surface. ${ }^{40}$ After silica coating and $-\mathrm{COOH}$ modification, the charge on the AuNRs reversed to $-17 \mathrm{mV}$, indicating the successful synthesis of AuNR@SiO $2-\mathrm{COOH}$ (Figure 3b).

The AuNR@SiO $\mathrm{S}_{2}-\mathrm{COOH}$ obtained were conjugated to CTORB via electrostatic bonding (CTO-RB-Au). After assembly of AuNRs, it was observed that AuNRs assembled the surface of nanofibers (Figure 6a). The UV-vis absorption of CTO-RB-Au combined the absorption spectra of CTO-RB and AuNR@SiO (Figure 6b). Under $980 \mathrm{~nm}$ excitation, the CTO nanofibers emit green light $\left({ }^{2} \mathrm{H}_{11 / 2},{ }^{4} \mathrm{~S}_{3 / 2} \rightarrow{ }^{4} I_{15 / 2}\right.$ transition) and red light $\left({ }^{4} \mathrm{~F}_{9 / 2}\right.$ $\rightarrow{ }^{4} I_{15 / 2}$ transition). As discussed previously, the green emission of CTO nanofibers under $980 \mathrm{~nm}$ irradiation was absorbed by RB molecules because of the overlap between RB molecules and green emission of CTO nanofibers. Comparing the UCPL spectrum of CTO nanofibers and the LSPR absorption of AuNRs, an overlap was also observed in the red part of the spectrum (Figure 6b). Therefore, the red emission was subsequently absorbed after the CTO-RB nanofibers were conjugated with AuNRs (Figure 4b). It should be noted that the aspect ratio of $\mathrm{Au}$ nanoparticles presents the plasmon wavelength of the longitudinal resonance. Careful tuning of the ratio between the length and diameter of the AuNRs results in an aspect ratio of $\sim 2$. In this study, a longitudinal
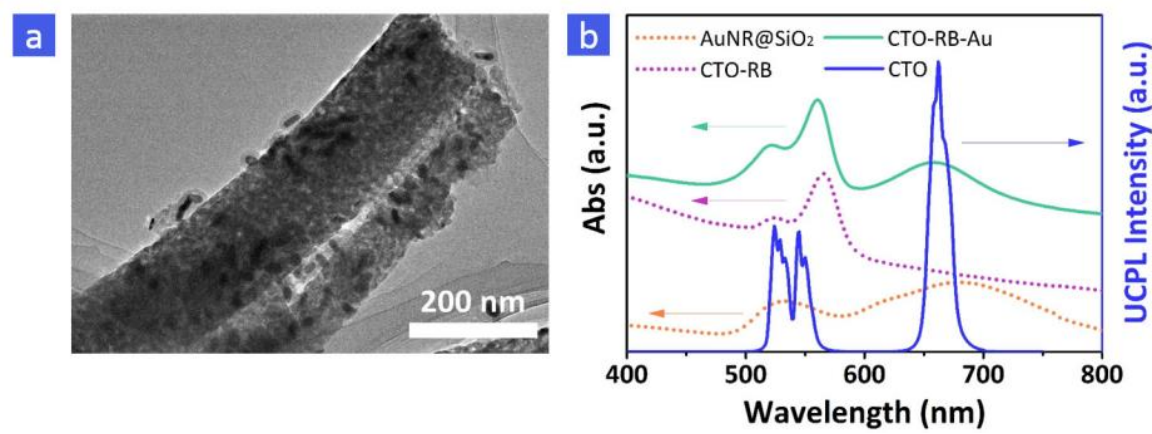

Figure 5 (a) TEM image of CTO-RB-Au nanocomposite; (b) UV-vis absorption spectra of CTO-RB, AuNR@SiO ${ }_{2}$ and CTO-RB-Au, and up-conversion emission spectrum of CTO nanofibers under $980 \mathrm{~nm}$ irradiation. 
plasmon resonance band at $\sim 660 \mathrm{~nm}$ was achieved, which is vital prerequisite for spectral matching to the red regime of $\mathrm{PL}$ emission from CTO nanofibers. This unique design enabled maximized absorption of emission from CTO nanofibers under $980 \mathrm{~nm}$ irradiation and the consequent photothermal conversion.

Therefore, the consistent absorption of RB molecules and

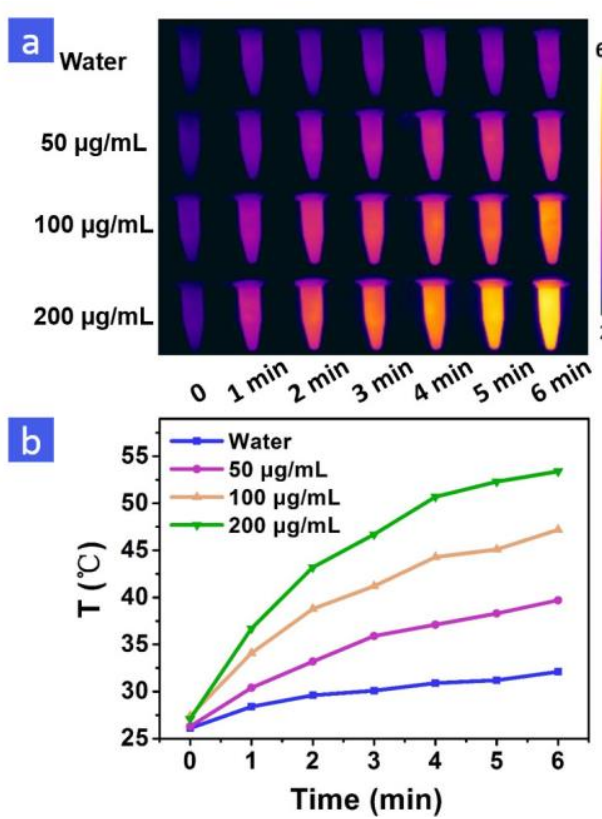

Figure 7 (a) Temperature images and (b) temperature variation of CTO-RB-Au nanocomposite solutions with different concentrations under irradiation by a $980-\mathrm{nm}$ laser with a power densitv of $1.5 \mathrm{~W} / \mathrm{cm}^{2}$ for 6 minutes.
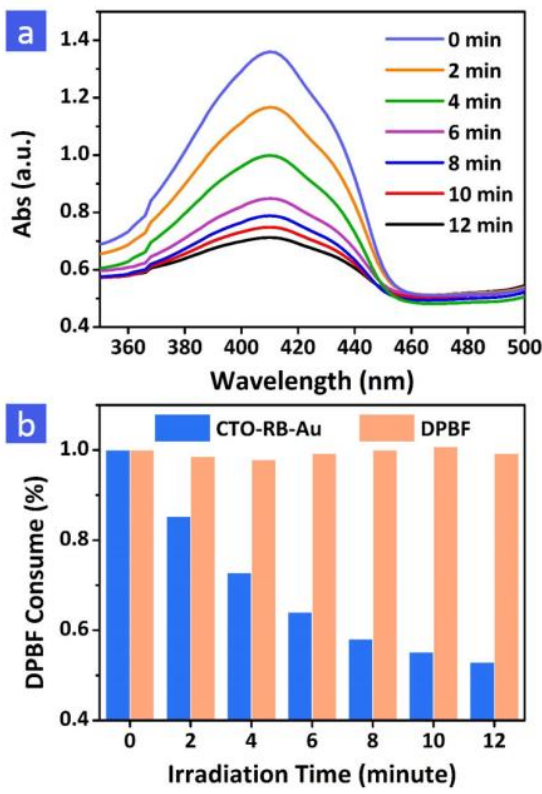

Figure 8 ROS generated from CTO-RB-Au nanocomposite. (a) UV-vis absorption spectra of a mixture of DPBF with CTORBHA-Au in ethanol under $980 \mathrm{~nm}$ irradiation $\left(1.5 \mathrm{~W} / \mathrm{cm}^{2}\right)$ for 0-12 min respectively. (b) Consumption of DPBF over time in the presence and absence of CTO-RB-Au.
AuNRs in the CTO-RB-Au nanocomposite implied that a single wavelength laser, that is $980 \mathrm{~nm}$, can be used to excite both PDT and PTT simultaneously.

\subsection{Photothermal and photodynamic effects}

The temperature changes of aqueous solutions containing nanofibers of different concentrations under $980 \mathrm{~nm}$ laser irradiation $\left(1.5 \mathrm{~W} / \mathrm{cm}^{2}\right)$ was investigated to examine the photothermal effect of CTO-RB-Au nanofibers. Figure 7a presents real-time photographs of the aqueous solutions with different amounts of nanofibers captured by an infrared thermal camera. The temperature of deionized water without nanofibers only increased by $6{ }^{\circ} \mathrm{C}$ after irradiation for $6 \mathrm{~min}$ (Figure 7b). In contrast, the temperature of CTO-RB-Au solution rose rapidly and strongly depended on the concentration of nanofibers. The temperature of the solution with a concentration of $200 \mu \mathrm{g} / \mathrm{mL}$, dramatically increased from $27.1{ }^{\circ} \mathrm{C}$ to $53.4{ }^{\circ} \mathrm{C}$ within 6 minutes. The findings confirm that the CTO-RB-Au nanocomposites can rapidly and efficiently convert the energy from $980 \mathrm{~nm}$ laser into thermal energy.

In addition to the photothermal effect, the ROS generation capability of CTO-RB-Au triggered by $980 \mathrm{~nm}$ light was also estimated using DPBF, a widely used chemical trapping reagent of ${ }^{1} \mathrm{O}_{2}$ that can irreversibly react with ${ }^{1} \mathrm{O}_{2} .{ }^{41,42}$ Under the irradiation of $980 \mathrm{~nm}$ light, the absorption of DPBF at 410 $\mathrm{nm}$ in pure DPBF solution remains unchanged (Figure 8). However, the absorbance of the solution containing CTO-RB$\mathrm{Au}$ and DPBF decreased gradually with the increasing of irradiation time, indicating the decomposition of DPBF. After 12 min irradiation, $50 \%$ of DPBF was consumed, illustrating the efficient generation of singlet oxygen.

\subsection{In vitro study}

\subsubsection{MTT assay}

To evaluate the potential for biomedical application, the biocompatibility of CTO, CTO-RB, and CTO-RB-Au was firstly investigated. Hep G2 cells were incubated with different concentrations of the materials for $24 \mathrm{~h}$ and were then evaluated using an MTT assay to quantify cell viability. The results show that the cell survival can be maintained above $89 \%$ from the lowest concentration of $12.5 \mu \mathrm{g} / \mathrm{mL}$ to the highest of $200 \mu \mathrm{g} / \mathrm{mL}$, confirming the satisfactory biocompatibility of the three samples (Figure 9a). In addition, the cell viability under the 980-nm irradiation $\left(1.5 \mathrm{~W} / \mathrm{cm}^{2}\right)$ for 6 min was examined in the absence of the test materials (Figure 9a), to test the effect of the laser power alone. Survival of the Hep G2 cells remained at more than $90 \%$, implying that the toxicity presented by the laser power density was minimal. .

As designed, the CTO-RB-Au nanocomposite has potential for both PDT and PTT when irradiated at $980 \mathrm{~nm}$. To assess the synergistic effect in vitro, the Hep G2 cell viability was quantified by changing the concentration of the nanocomposites and exposure time, respectively. As shown in Figure 9b, most of the cancer cells stayed alive when incubated with pure CTO nanofibers even under irradiation of NIR light. The fact that there was some limited levels of cell death in the highest concentration of $200 \mu \mathrm{g} / \mathrm{mL}$ can be attributed to the slight temperature rise caused by NIR light. When 

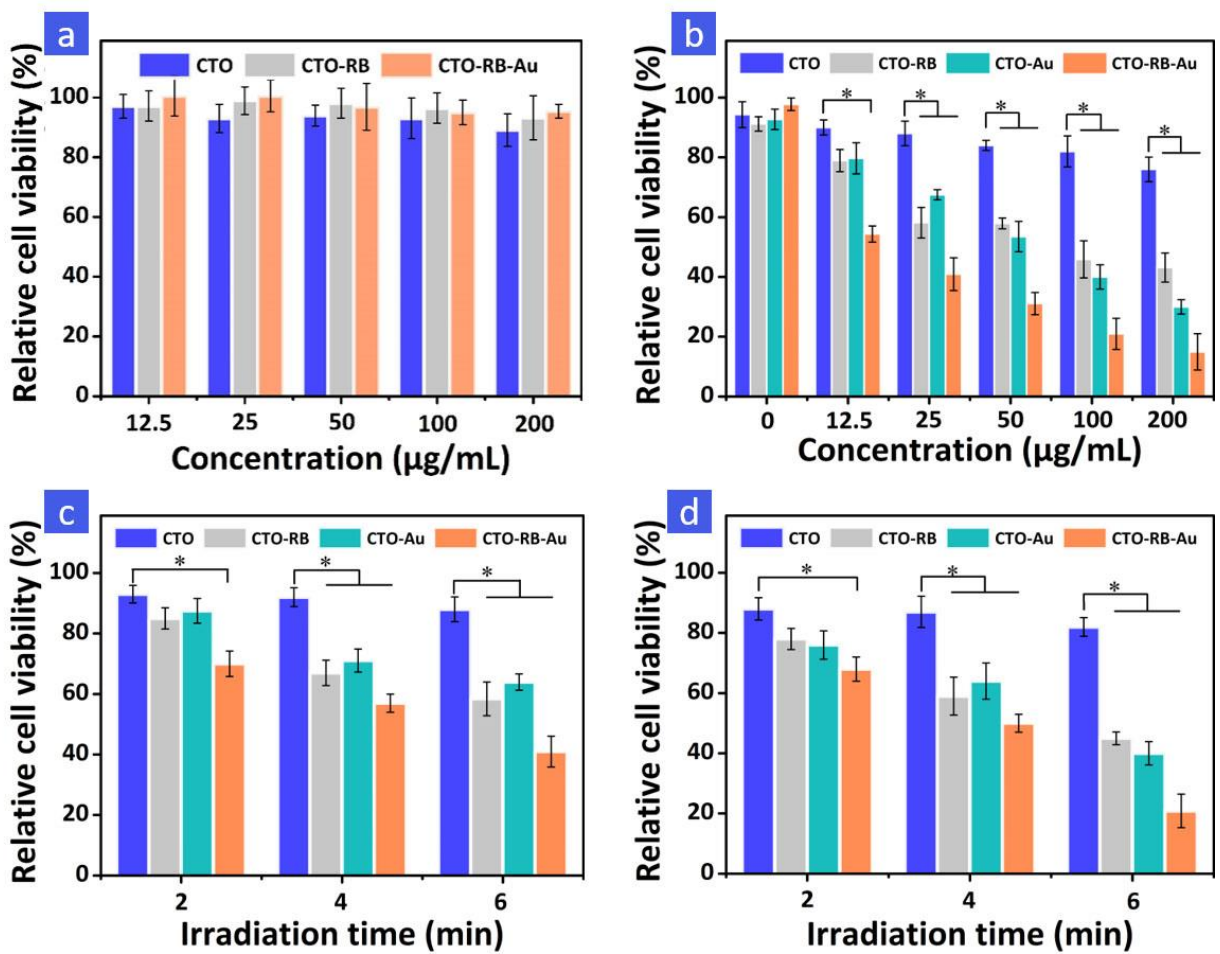

Figure 9 Relative cell viability of Hep G2 cells incubated with CTO, CTO-RB, and CTO-RB-Au. Cell viability at different concentrations $(12.5-200 \mu \mathrm{g} / \mathrm{mL})$ for $24 \mathrm{~h}(\mathrm{a})$ in the absence and (b) presence of $980 \mathrm{~nm}$ irradiation $\left(1.5 \mathrm{~W} / \mathrm{cm}^{2}\right)$ for $6 \mathrm{~min}$. Cell viability depended on irradiation time $(2-6 \mathrm{~min})$ at concentration of (c) $25 \mu \mathrm{g} / \mathrm{mL}$ and (d) $100 \mu \mathrm{g} / \mathrm{mL}$ under $980 \mathrm{~nm}$ irradiation $\left(1.5 \mathrm{~W} / \mathrm{cm}^{2}\right),{ }^{*} \mathrm{p}<0.05$.

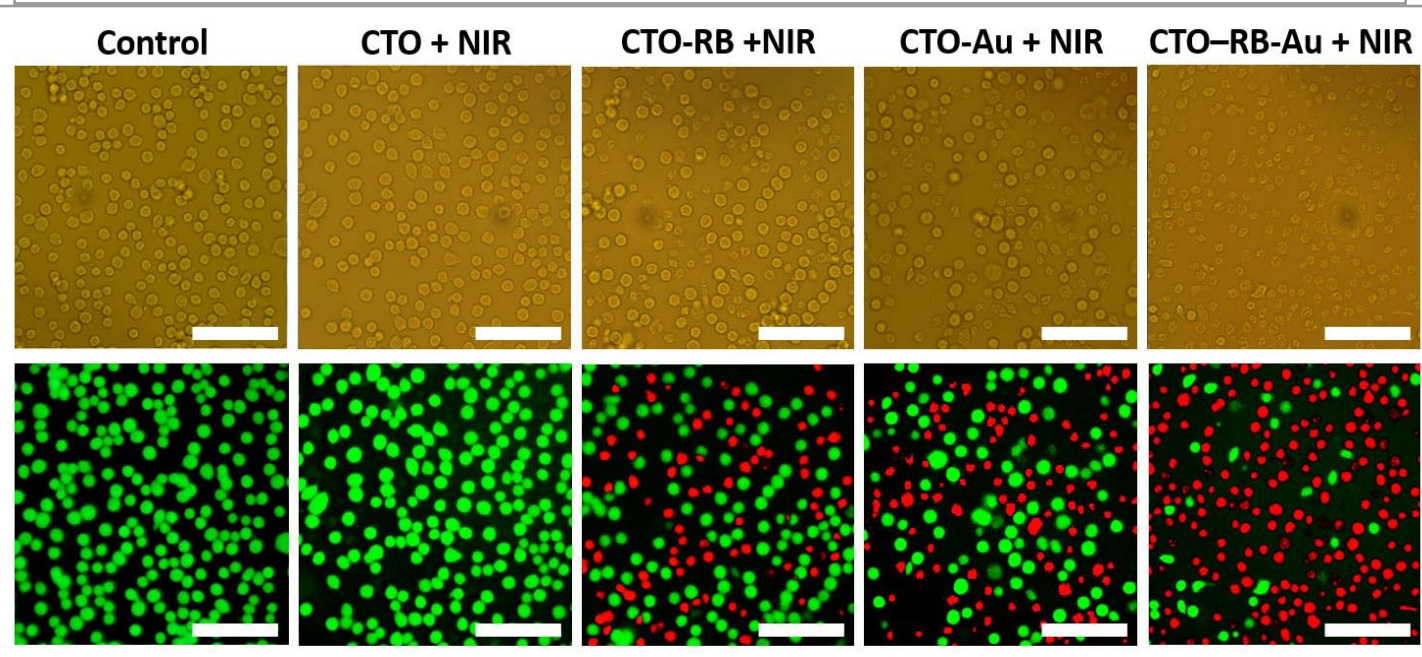

Figure 10 The bright field and fluorescence images of Calcein AM and PI co-staining Hep G2 cells cultured with CTO, CTO-RB, CTO-Au and CTO-RB-Au under $980 \mathrm{~nm}$ irradiation $\left(1.5 \mathrm{~W} / \mathrm{cm}^{2}, 6 \mathrm{~min}\right.$ ) with a nanofiber concentration of $100 \mu \mathrm{g} / \mathrm{mL}$. Scale bars: $100 \mu \mathrm{m}$.

RB molecules were linked with CTO nanofibers there was a significant reduction in cell viability compared with pure СTO nanofibers and there was a dose-dependent photodynamic effect. A similar phenomenon was observed in the CTO-Au nanocomposite. About $60 \%$ of Hep G2 cells were viable following single photodynamic or photothermal treatment with a concentration of $25 \mu \mathrm{g} / \mathrm{mL}$ and exposure to irradiation for $6 \mathrm{~min}$. While when CTORB nanofibers were combined with AuNRs, the cell viability was dramatically decreased. Using a nanofiber concentration of 200 $\mu \mathrm{g} / \mathrm{mL}$, the cell viability declined to only $15 \%$, while for the CTO-RB sample, the figure was $\sim 43 \%$. This shows that the in vitro anticancer efficacy of synergistic phototherapy is amplified 3 times as compared to the photodynamic approach alone. Moreover, as expected, the cell viability decreased with increasing irradiation time for the concentrations of $100 \mu \mathrm{g} / \mathrm{mL}$ and $25 \mu \mathrm{g} / \mathrm{mL}$ (Figure $9 c \& d)$. The results demonstrate that the CTO-RB-Au nanocomposite combining PDT and PTT has the potential to deliver cancer therapy with significantly improved efficiency. 


\subsubsection{Live/dead cell staining}

The combined effects of PDT and PTT for CTO-RB-Au were further verified with Calcein AM and PI co-staining. Using $980 \mathrm{~nm}$ laser treatment, no obvious cell death was observed when cells were cultured with- the CTO nanofibers (Figure 10). However, in the CTORB and CTO-Au group, the number of live cells decreased as compared with the control group, indicating the cytotoxicity of ROS and the heat effect generated by CTO-RB and CTO-Au under excitation by the $980-\mathrm{nm}$ laser, respectively. Furthermore, cell death was dramatically increased with CTO-RB-Au, as indicated by the sparse green fluorescence from live cells. The results agree with the MTT assay in Figure 9, clearly demonstrating again the efficient PDT/PTT effect of the CTO-RB-Au composite.

\section{Conclusions}

In summary, CTO-RB-Au nanocomposites have been successfully fabricated for use in an implantable device designed for use with combined photodynamic and photothermal therapy. In the composite, RB and AuNRs served as the PDT and PTT agents, respectively. Since RB and AuNRs have matched absorption with the green and red emissions of UCPL CTO nanofibers respectively, a laser with continuous single wavelength can be employed to induce the PDT and PTT effects simultaneously. Using $980 \mathrm{~nm}$ irradiation, the nanocomposite can convert energy effectively from NIR light to induce a combination of heat and ROS generation. Moreover, the results from in vitro experiments demonstrated that this simultaneous therapeutic approach was significantly more effective than PDT alone. The synergistic combination of PDT and PTT thus holds promise for future applications in multiple anticancer therapies.

\section{Experimental section}

\subsection{Synthesis of CTO nanofibers}

A method for the preparation and electospinning of CTO nanofibers has been reported previously. ${ }^{27,} 28$ Briefly, a typical sol-gel approach was used to prepare the precursor solution for electrospinning. Tetrabutyl titanate $(\sim 0.82 \mathrm{~g}), \quad \mathrm{Ca}\left(\mathrm{NO}_{3}\right)_{2} \cdot 4 \mathrm{H}_{2} \mathrm{O} \quad(\sim 0.45 \mathrm{~g})$, $\mathrm{Yb}\left(\mathrm{NO}_{3}\right)_{3} \cdot 5 \mathrm{H}_{2} \mathrm{O}(\sim 0.19 \mathrm{~g})$ and $\mathrm{Er}\left(\mathrm{NO}_{3}\right)_{3} \cdot 5 \mathrm{H}_{2} \mathrm{O}(\sim 0.02 \mathrm{~g})$ were mixed with acetic acid $(2 \mathrm{~mL})$, ethanol $(7 \mathrm{~mL})$ and $\mathrm{N}, \mathrm{N}$-dimethylformamide (DMF, $3 \mathrm{~mL}$ ) by stirring for $3 \mathrm{~h}$. Then $0.6 \mathrm{~g}$ of poly(vinylpyrrolidone) (PVP, $M W=1,300,000$, Aladdin), $0.2 \mathrm{~g}$ of Pluronic ${ }^{\circledR}$ F127 $\left(\mathrm{EO}_{106} \mathrm{PO}_{70} \mathrm{EO}_{106}\right)$ and $0.5 \mathrm{~mL}$ of acetyl acetone were added and stirred overnight to obtain a homogeneous solution.

During the electrospinning process, the precursor was fed into a stainless-steel needle at $0.4 \mathrm{~mL} / \mathrm{h}$. When a voltage of $6-8 \mathrm{kV}$ was applied to the needle, a stable cone-jet electrospinning mode was achieved and this was monitored using a high-speed camera (Baumer, TXG04h, Germany). Uniform precursor nanofibers were formed and collected on aluminum foil. After the product had been vacuum-dried at $80^{\circ} \mathrm{C}$ for $12 \mathrm{~h}$ to remove the residual solvent, the nanofibers were calcined at $700{ }^{\circ} \mathrm{C}$ for $2 \mathrm{~h}$ in air.

\subsection{Surface decoration of СТО nanofibers}

СTO nanofibers were firstly modified with amino groups using a protocol adapted from work by Maldiney et al. ${ }^{43}$ and our previous work ${ }^{27,} 28$, in which $100 \mathrm{mg}$ of CTO nanofibers were dispersed in $\mathrm{NaOH}$ aqueous solution ( $80 \mathrm{~mL}, 5 \mathrm{mM}$ ) under stirring for $12 \mathrm{~h}$. Then the nanofibers were collected, washed, and dried. Thereafter, the obtained nanofibers were mixed with $500 \mu \mathrm{L}$ of (3-aminopropyl) triethoxysilane (APTES, Aladdin) in $40 \mathrm{~mL}$ of DMF by stirring at $80^{\circ} \mathrm{C}$ for $24 \mathrm{~h}$. Then the amino modified CTO nanofibers were washed with DMF and collected by centrifugation.

\subsection{Linking of RB with CTO nanofibers}

To improve the reactivity of the carboxyl group for RB, RB hexanoic acid ester (RB-HA) was firstly synthesized using a method described by Lamberts et al.. ${ }^{29}$ Briefly, $100 \mathrm{mg}$ of RB was reacted with $20 \mathrm{mg}$ of 6-bromohexanoic acid in $25 \mathrm{~mL} \mathrm{DMF}$ at $70{ }^{\circ} \mathrm{C}$ for $24 \mathrm{~h}$ to obtain RB-HA aqueous solution. Subsequently, tris-(2-hydroxyethyl)-amine (TEA, $80 \mu \mathrm{L}$ ), N-hydroxysuccinimide (NHS, $60 \mathrm{mg}$ ) and $\mathrm{N}$-(3dimethylaminopropyl)- $\mathrm{N}^{\prime}$-ethylcarbodiimide hydrochloride (EDC, $120 \mathrm{mg}$ ) were added into the RB-HA solution and stirred at $30^{\circ} \mathrm{C}$ for $1 \mathrm{~h}$. Our novel step was to then introduce $60 \mathrm{mg}$ of CTO- $-\mathrm{NH}_{2}$ nanofibers into the solution. The mixture was stirred for $24 \mathrm{~h}$ to obtain RB-HA conjugated СTO nanofibers. All experiments were undertaken in black-out conditions.

\subsection{Synthesis of gold nanorods}

\subsubsection{Seed solution}

The gold nanorods (AuNRs) were fabricated according to the wellestablished seed-mediated growth method with some modifications. ${ }^{32}$ Briefly, CTAB aqueous solution $(5 \mathrm{~mL}, 0.2 \mathrm{M}$ ) was mixed with $\mathrm{HAuCl}_{4}(5 \mathrm{~mL}, 0.5 \mathrm{mM})$ and ice-cold $\mathrm{NaBH}_{4}(0.6 \mathrm{~mL}$, $0.01 \mathrm{M}$ ) under vigorous stirring for $2 \mathrm{~min}$. Then the brownish-yellow seed solution was aged at room temperature for $30 \mathrm{~min}$ before use.

\subsubsection{Growth solution}

The growth solution was made from solutions of CTAB $(50 \mathrm{~mL}, 0.1$ $\mathrm{M})$, sodium salicylate $(0.16 \mathrm{~g}), \mathrm{HAuCl}_{4}(50 \mathrm{~mL}, 1 \mathrm{mM}), \mathrm{AgNO}_{3}(1.2$ $\mathrm{mL}, 4 \mathrm{mM})$ and ascorbic acid $(0.2 \mathrm{~mL}, 0.064 \mathrm{M})$. The growth solution became colorless after gentle stirring. The gold seed solution $(0.16$ $\mathrm{mL}$ ) was then injected into the growth solution and the mixture was stirred for $30 \mathrm{~s}$ and left undisturbed at $30{ }^{\circ} \mathrm{C}$ overnight. The gold nanorods obtained were centrifuged, washed with deionized water to removed excess $C T A B$ and dispersed in $10 \mathrm{~mL}$ of water for further use.

\subsection{Synthesis of carboxyl-modified silica-coated gold nanorods}

Carboxyl-modified silica-coated gold nanorods (AuNR@SiO ${ }_{2}-\mathrm{COOH}$ ) were prepared based on a modified version of a method reported previously. ${ }^{44,45}$ The as-synthesized AuNRs in $10 \mathrm{~mL}$ of water was mixed with $\mathrm{NaOH}$ aqueous solution $(0.1 \mathrm{~mL}, 0.1 \mathrm{M})$ under stirring. Then $100 \mu \mathrm{L}$ of $5 \%$ TEOS in methanol were added three times at 30 min intervals, and the mixture was reacted for $12 \mathrm{~h}$. The obtained AuNR@SiO ${ }_{2}$ were centrifuged, washed with deionized water several times, and re-dispersed in $5 \mathrm{~mL}$ of ethanol for further use.

The AuNR@SiO ${ }_{2}$ solution and $40 \mu \mathrm{L}$ of APTES were mixed in 40 $\mathrm{mL}$ of DMF and stirred for $24 \mathrm{~h}$. Then the obtained amino modified 
AuNR@SiO $\left(\right.$ AuNR@SiO $-\mathrm{NH}_{2}$ ) were centrifuged and redispersed in $5 \mathrm{~mL}$ of ethanol.

The AuNR@SiO $2-\mathrm{NH}_{2}$ solution, $40 \mathrm{mg}$ of succinic anhydride (SA) and $40 \mathrm{mg}$ of triethylamine were added into $5 \mathrm{~mL}$ DMSO and stirred in $40{ }^{\circ} \mathrm{C}$ for $48 \mathrm{~h}$ to obtain AuNR@ $\mathrm{SiO}_{2}-\mathrm{COOH}$. $20 \mathrm{mg}$ of AuNR@SiO $2-\mathrm{COOH}$ and $40 \mathrm{mg}$ of the CTO nanofibers were combined by stirring for $24 \mathrm{~h}$ to obtain a AuNR conjugated CTO nanocomposite (CTO-Au). Similarly, $20 \mathrm{mg}$ of AuNR@ $\mathrm{SiO}_{2}-\mathrm{COOH}$ and $40 \mathrm{mg}$ of the CTO-RB composite were combined by stirring for $24 \mathrm{~h}$ to obtain RB and AuNRs co-conjugated CTO nanocomposite.

\subsection{Examination of photothermal performance}

The photothermal effect of CTO-RB-Au solutions with different concentrations $(0,50,100,200 \mu \mathrm{g} / \mathrm{mL})$ were estimated using a 980 $\mathrm{nm}$ laser at a power density of $1.5 \mathrm{~W} / \mathrm{cm}^{2}$ for up to $6 \mathrm{~min}$ at room temperature using a fiber coupled laser source (Stone laser system AC90-260V/50-60HZ, China). An infrared thermal imaging instrument (FLIR, E40) was used to measure and map the change of temperature.

\subsection{Detection of singlet oxygen generation}

Singlet oxygen generation irradiated by $980 \mathrm{~nm}$ light was measured by the absorption of a chemical probe, 3-diphenylisobenzofuran (DPBF). $2 \mathrm{~mL}$ of CTO-RB-Au ethanol solution $(5 \mathrm{mg} / \mathrm{mL}$ ) were mixed with $1 \mathrm{~mL}$ of DPBF ethanol solution $(50 \mathrm{mM})$. Absorbance of the solution at $410 \mathrm{~nm}$ was recorded every $1 \mathrm{~min}$. The generation of ${ }^{1} \mathrm{O}_{2}$ was determined from the decline of the absorption of DPBF. Absorption of DPBF solution under irradiation in the absence of materials was also recorded as a negative control.

\subsection{Preliminary in vitro study}

Human Hep G2 liver cancer cells were used to examine the in vitro antitumor potentials of CTO-RB-Au platform. The cytotoxicity of CTO, CTO-RB, СTO-Au and CTO-RB-Au was determined using a 3(4,5-dimethylthiazol-2-yl)-2,5-diphenyltetrazolium bromide (MTT) cell assay. Hep $\mathrm{G} 2$ cells were seeded in a 96 -well plate at a density of 8000 cells per well and incubated at $37{ }^{\circ} \mathrm{C}$ for $24 \mathrm{~h}$. Then the culture media was replaced with fresh culture medium containing CTO, CTO-RB, СТO-Au and CTO-RB-Au nanocomposites at different concentrations. To study the photodynamic and photothermal effect, the nanocomposites were irradiated using a 980-nm laser for 0-6 minutes with an energy density of $1.5 \mathrm{~W} / \mathrm{cm}^{2}$. After incubation for $24 \mathrm{~h}, 10 \mu \mathrm{L}$ of MTT solution was added into each well and cultured for $4 \mathrm{~h}$. Then the original medium was removed and formazan (MTT metabolic product) was dissolved with dimethyl sulfoxide (DMSO, $100 \mu \mathrm{L}$ per well). The absorbance of the solution was measured at $490 \mathrm{~nm}$ using a microplate reader (Tecan 50, The Switzerland). The anticancer effect was further visualized using calcein acetoxymethyl ester (calcein AM) and propidium iodide (PI) staining and observed with a fluorescent microscope (Nexcope, The USA). The samples (not irradiated and/or not treated with nanocomposite) were used as a test control. Similarly, the cytocompatibility of samples was examined using an MTT assay with Hep G2 cells, following the same procedure above.

\subsection{Characterization}

The microstructure and morphology of materials were visualized by a Hitachi SU-70 field-emission scanning electron microscope (FESEM) and a FEI Tecnai F20 high-resolution transmission electron microscope (HRTEM). A thermo ARL X'TRA powder diffractometer was used to record the X-ray diffraction (XRD) patterns. FTIR spectra were evaluated using a Perkin-Elmer 580B infrared spectrophotometer (Tensor 27, Bruker). A Zetasizer (Zetasizer 3000 HSA, Malvern) was used to determine the zeta potential of samples at room temperature. The UV-vis-NIR absorption spectra were examined by TU-1810 UV-vis spectrophotometer. The UCPL spectra were recorded using a fluorescence spectrophotometer (PL, FLSP920, Edinburgh) under the excitation of a $980 \mathrm{~nm}$ laser. The fiber diameter and the size of gold nanorods were measured from SEM or TEM micrographs using image analysis $(n=50)$.

\subsection{Statistical Analysis}

Data were expressed as mean \pm standard deviation (SD). All statistical data were obtained using a two-tailed Student's t test. A value of $p<0.05$ was taken as statistically significant.

\section{Acknowledgements}

This work was financially supported by the National Nature Science Foundation of China (51232006 and 51672247), the '111' Program funded by Education Ministry of China and State Administration of Foreign Experts Affairs (B16043), the Major State Research Program of China (2016YFC1101900), and the Nature Science Foundation of Zhejiang Province (LY15E020005).

\section{Notes and references}

1. L. A. Torre, F. Bray, R. L. Siegel, J. Ferlay, J. Lortet-Tieulent and A. Jemal, CA-Cancer J. Clin., 2015, 65, 87-108.

2. X.-B. Xiong and A. Lavasanifar, ACS Nano, 2011, 5, 52025213.

3. D. B. Longley and P. G. Johnston, J. Pathol., 2005, 205, 275292.

4. C. S. Gutsche, M. Ortwerth, S. Gräfe, K. J. Flanagan, M. O. Senge, H.-U. Reissig, N. Kulak and A. Wiehe, Chem-Eur J, 2016, 22, 13953-13964.

5. G. Chang, Y. Wang, B. Gong, Y. Xiao, Y. Chen, S. Wang, S. Li, F. Huang, Y. Shen and A. Xie, ACS Appl. Mater. Interfaces, 2015, 7, 11246-11256.

6. Q. Chen, C. Wang, L. Cheng, W. He, Z. Cheng and Z. Liu, Biomaterials, 2014, 35, 2915-2923.

7. C. Qin, J. Fei, A. Wang, Y. Yang and J. Li, Nanoscale, 2015, 7, 20197-20210.

8. M. Yu, F. Guo, J. Wang, F. Tan and N. Li, ACS Appl. Mater. Interfaces, 2015, 7, 17592-17597.

9. M. G. Walker, P. J. Jarman, M. R. Gill, X. Tian, H. Ahmad, P. A. N. Reddy, L. McKenzie, J. A. Weinstein, A. J. H. M. Meijer, G. Battaglia, C. G. W. Smythe and J. A. Thomas, Chem-Eur J, 2016, 22, 5996-6000.

10. R. Weissleder, Nat Biotech, 2001, 19, 316-317.

11. D. Zhang, M. Wu, Y. Zeng, L. Wu, Q. Wang, X. Han, X. Liu and J. Liu, ACS Appl. Mater. Interfaces, 2015, 7, 8176-8187. 
12. B. Wang, J.-H. Wang, Q. Liu, H. Huang, M. Chen, K. Li, C. Li, X.-F. Yu and P. K. Chu, Biomaterials, 2014, 35, 1954-1966.

13. L. Liang, Y. Lu, R. Zhang, A. Care, T. A. Ortega, S. M. Deyev, Y. Qian and A. V. Zvyagin, Acta Biomater., 2017, 51, 461-470.

14. Q. Sun, Q. You, X. Pang, X. Tan, J. Wang, L. Liu, F. Guo, F. Tan and N. Li, Biomaterials, 2017, 122, 188-200.

15. B. Du, X. Gu, W. Zhao, Z. Liu, D. Li, E. Wang and J. Wang, J. Mater. Chem. B, 2016, 4, 5842-5849.

16. M. Nurunnabi, Z. Khatun, G. R. Reeck, D. Y. Lee and Y.-k. Lee, ACS Appl. Mater. Interfaces, 2014, 6, 12413-12421.

17. H. Gong, L. Cheng, J. Xiang, H. Xu, L. Feng, X. Shi and Z. Liu, Adv. Funct. Mater., 2013, 23, 6059-6067.

18. X. Sun, B. Dong, H. Xu, S. Xu, X. Zhang, Y. Lin, L. Xu, X. Bai, S. Zhang and H. Song, ACS Appl. Mater. Interfaces, 2017, 9, 11451-11460.

19. L. Yan, Z. Wang, X. Chen, X.-J. Gou, Z. Zhang, X. Zhu, M. Lan, W. Chen, G. Zhu and W. Zhang, Chem. Commun., 2017, 53, 2339-2342.

20. A. E. O'Connor, W. M. Gallagher and A. T. Byrne, Photochem. Photobiol., 2009, 85, 1053-1074.

21. X. Tan, J. Wang, X. Pang, L. Liu, Q. Sun, Q. You, F. Tan and N. Li, ACS Appl. Mater. Interfaces, 2016, 8, 34991-35003.

22. R. De Souza, P. Zahedi, C. J. Allen and M. Piquette-Miller, Drug Delivery, 2010, 17, 365-375.

23. J. B. Wolinsky, Y. L. Colson and M. W. Grinstaff, J. Controlled Release, 2012, 159, 14-26.

24. P. Huang, K. W. Xu and Y. Han, Mater. Lett., 2005, 59, 185189.

25. H. Tang and F. Wang, Mater. Lett., 2013, 93, 427-430.

26. J. P. Wiff, V. M. Fuenzalida, J. L. Arias and M. S. Fernandez, Mater. Lett., 2007, 61, 2739-2743.

27. H. Liu, Y. Fu, Y. Li, Z. Ren, X. Li, G. Han and C. Mao, Langmuir, 2016, 32, 9083-9090.

28. X. Li, Q. Zhang, Z. Ahmad, J. Huang, Z. Ren, W. Weng, G. Han and C. Mao, J. Mater. Chem. B, 2015, 3, 7449-7456.

29. J. J. M. Lamberts, D. R. Schumacher and D. C. Neckers, J. Am. Chem. Soc., 1984, 106, 5879-5883.

30. B. Muñoz, A. Rámila, J. Pérez-Pariente, I. Díaz and M. ValletRegí, Chem. Mater., 2003, 15, 500-503.

31. S. W. Prasanna, G. Poorani, M. S. Kumar, P. Aruna and S. Ganesan, Mater. Express, 2014, 4, 359-366.

32. X. Ye, L. Jin, H. Caglayan, J. Chen, G. Xing, C. Zheng, V. DoanNguyen, Y. Kang, N. Engheta, C. R. Kagan and C. B. Murray, ACS Nano, 2012, 6, 2804-2817.

33. X. Hu and X. Gao, Phys. Chem. Chem. Phys., 2011, 13, 10028-10035.

34. C.-W. Chen, P.-H. Lee, Y.-C. Chan, M. Hsiao, C.-H. Chen, P. C. Wu, P. R. Wu, D. P. Tsai, D. Tu, X. Chen and R.-S. Liu, J. Mater. Chem. B, 2015, 3, 8293-8302.

35. L. C. Chen, C. W. Wei, J. S. Souris, S. H. Cheng, C. T. Chen, C. S. Yang, P. C. Li and L. W. Lo, J. Biomed. Opt., 2010, 15, 6.

36. Y. S. Chen, W. Frey, S. Kim, K. Homan, P. Kruizinga, K. Sokolov and S. Emelianov, Opt. Express, 2010, 18, 88678877.

37. Z. Zhang, L. Wang, J. Wang, X. Jiang, X. Li, Z. Hu, Y. Ji, X. Wu and C. Chen, Adv. Mater., 2012, 24, 1418-1423.

38. D.-W. Wang, X.-M. Zhu, S.-F. Lee, H.-M. Chan, H.-W. Li, S. K. Kong, J. C. Yu, C. H. K. Cheng, Y.-X. J. Wang and K. C.-F. Leung, J. Mater. Chem. B, 2013, 1, 2934-2942.

39. F. Liu, J. Wang, P. Huang, Q. Zhang, J. Deng, Q. Cao, J. Jia, J. Cheng, Y. Fang, D. Y. B. Deng and W. Zhou, J. Mater. Chem. $B, 2015,3,2206-2214$.
40. B.-K. Wang, X.-F. Yu, J.-H. Wang, Z.-B. Li, P.-H. Li, H. Wang, L. Song, P. K. Chu and C. Li, Biomaterials, 2016, 78, 27-39.

41. D. Yang, G. Yang, S. Gai, F. He, R. Lv, Y. Dai and P. Yang, ACS Biomater.-Sci. Eng., 2016, 2, 2058-2071.

42. X.-S. Ke, Y. Ning, J. Tang, J.-Y. Hu, H.-Y. Yin, G.-X. Wang, Z.-S. Yang, J. Jie, K. Liu, Z.-S. Meng, Z. Zhang, H. Su, C. Shu and J.L. Zhang, Chem-Eur J, 2016, 22, 9676-9686.

43. T. Maldiney, A. Bessiere, J. Seguin, E. Teston, S. K. Sharma, B. Viana, A. J. J. Bos, P. Dorenbos, M. Bessodes, D. Gourier, D. Scherman and C. Richard, Nat. Mater., 2014, 13, 418-426.

44. Q. Jia, J. Ge, W. Liu, S. Liu, G. Niu, L. Guo, H. Zhang and P. Wang, Nanoscale, 2016, 8, 13067-13077.

45. W.-C. Wu and J. B. Tracy, Chem. Mater., 2015, 27, 28882894. 